\title{
Pemahaman Informal Murid Tahun Lima Tentang Perkadaran
}

\author{
Fazura Mohd Noor*, Sharifah Norul Akmar Syed Zamri, Leong Kwan Eu \\ Jabatan Pendidikan Matematik dan Sains, Fakulti Pendidikan, Universiti Malaya, 50603 Kuala Lumpur \\ *Corresponding author: cikgufazu@siswa.um.edu.my
}

\begin{abstract}
This study aims to identify primary school pupils' informal understanding and solving problems strategies related to proportional. This qualitative study involved Year Five pupils who were selected through purposive sampling. Data were collected using clinical interview technique can show the pupils' strategies and in-depth justification for each activity is shown. This article presents the analysis of the pupils' responses related to two proportional tasks. Data shows that students used various informal strategies to solve proportional problems. The findings also showed that students who have not learn ratio and proportion topic formally, could show proportional reasoning elements, such as unitizing, partitioning, and changes and quantities. The findings of this study may provide information to mathematics teachers that every student has different informal strategy to solve proportional problems based on their experiences and prior knowledge. Thus teachers need to diversify activities to encourage students' proportional thinking.
\end{abstract}

Keywords: Informal understanding; proportional problems; strategies

\begin{abstract}
Abstrak
Kajian ini bertujuan untuk mengenal pasti strategi informal penyelesaian murid sekolah rendah berkaitan masalah perkadaran. Kajian kualitatif ini melibatkan murid Tahun Lima yang dipilih melalui pensampelan bertujuan. Data kajian yang telah dikumpulkan melalui teknik temu bual klinikal dapat memaparkan strategi informal dan justifikasi murid secara mendalam bagi setiap aktiviti yang ditunjukkan. Artikel ini hanya membentangkan analisis ke atas respons murid terhadap dua tugas berkaitan masalah perkadaran Data menunjukkan bahawa murid menggunakan pelbagai strategi informal untuk menyelesaikan masalah perkadaran. Dapatan juga menunjukkan bahawa murid yang belum pernah mempelajari topik kadaran secara formal boleh mempamerkan elemen penaakulan perkadaran, seperti unitizing, pemetakan, dan kuantiti dan perubahan. Dapatan kajian ini dapat membekalkan informasi kepada guru matematik bahawa setiap murid mempunyai strategi informal menyelesaikan masalah perkadaran yang berbeza berdasarkan pengalaman dan pengetahuan sedia ada. Maka guru perlu mempelbagaikan aktiviti yang dapat menggalakkan murid berfikir secara perkadaran.
\end{abstract}

Kata Kunci: Pemahaman informal; masalah perkadaran; strategi

(C) 2017 Penerbit UTM Press. All rights reserved

\subsection{PENGENALAN}

Penaakulan perkadaran yang menggunakan konsep nisbah dan kadaran bukan sahaja dianggap sebagai penghubung antara nombor, aritmetik, algebra, dan matematik lanjutan (Lesh, Post, \& Behr, 1988; Fuson \& Abrahamson, 2005; Lamon, 2007), malah penaakulan perkadaran dalam topik nisbah dan kadaran turut diajar secara formal bermula dari Gred Lima hingga Gred Lapan (National Council of Teaching of Mathematics, 2000). Kebanyakan kandungan buku teks di sekolah bagi topik nisbah dan kadaran mengandungi satu set prosedur dan algoritma (Cramer, Post, \& Currier, 1993) yang mana murid pertama kali diperkenalkan kepada kaedah lebih formal, iaitu kaedah pendaraban silang semasa menyelesaikan masalah berkaitan perkadaran. Kaedah pembelajaran secara formal ini menyebabkan murid kurang mengaplikasi konsep nisbah dan kadaran, tetapi lebih menguasai sesuatu prosedur dan algoritma bagi mendapatkan jawapan. Ini menyebabkan murid mengalami masalah untuk memulakan penyelesaian masalah oleh kerana kebiasaan mereka membuat latihan yang hanya memerlukan menghafal rumus dan mengingat kembali prosedur penyelesaian (Lara Roth, 2006) tanpa memahami mengapa perlu berbuat demikian. Justeru murid perlu diberi peluang dalam pembelajaran nisbah dan kadaran agar dapat membantu mengembangkan penaakulan perkadaran dan berkeupayaan menyelesaikan masalah perkadaran.

Walaupun kajian (Christou \& Philippou, 2002; Missailidou \& Williams, 2003) mengenal pasti strategi murid dalam menyelesaikan masalah perkadaran telah dilakukan, namun setakat ini masih belum banyak kajian mengenal pasti strategi informal dan justifikasi tentang perkadaran murid di peringkat sekolah rendah sebelum mempelajari secara formal terutama dalam konteks negara Malaysia. Di Malaysia, kurikulum standard sekolah rendah (Kementerian Pendidikan Malaysia, 2013) telah memperkenalkan topik nisbah dan kadaran bermula tahun 2014. Adalah penting bagi guru mengetahui dan mengenal pasti strategi informal penaakulan perkadaran yang dimiliki murid dan bagaimana mereka memberi justifikasi bagi menyokong setiap aktiviti matematik yang dilakukan sebelum mempelajari secara formal. Secara ringkasnya, kajian ini bertujuan untuk mengenal pasti persoalan kajian berikut: apakah strategi informal dan justifikasi yang ditunjukkan oleh murid Tahun Lima semasa menyelesaikan masalah berkaitan perkadaran? 


\subsection{LATAR BELAKANG TEORITIKAL}

\section{Penaakulan Perkadaran}

Penaakulan perkadaran merupakan salah satu kemahiran yang perlu dikuasai oleh murid sebagai persediaan dalam pembelajaran matematik di peringkat yang lebih tinggi. Murid yang berkebolehan berfikir secara perkadaran menunjukkan mereka memahami hubungan multiplikatif antara dua kuantiti (Lamon, 2007). Beberapa konteks masalah yang melibatkan pemahaman hubungan multiplikatif termasuklah masalah yang melibatkan nisbah, kadar, dan kadaran. Oleh kerana penaakulan perkadaran sering digunakan dalam konteks kehidupan seharian, maka pendedahan masalah penaakulan perkadaran di peringkat awal dapat memberi peluang murid mengembangkan penaakulan perkadaran. Dua jenis masalah yang kerap digunakan untuk mengenal pasti penaakulan perkadaran murid, iaitu masalah missing-value dan masalah membandingkan nisbah (Ben-Chaim, Fey, Fitzgerald, Benedetto, \& Miller, 1998; Heller, Post, Behr, \& Lesh, 1990). Secara khusus, Lamon (2007) mencadangkan enam komponen yang terlibat dalam penaakulan perkadaran, iaitu pemikiran relatif, unitizing, pemetakan, interpretasi nombor rasional, kepekaan nisbah (ratio sense), dan kuantiti dan perubahan.

\section{Pemahaman Informal}

Walaupun topik nisbah dan kadaran yang melibatkan konsep multiplikatif merupakan asas bagi pembelajaran matematik di peringkat sekolah menengah, murid sering kali menghadapi kesukaran semasa mempelajari topik tersebut. Namun begitu, Lamon (1993) mendapati murid Gred Enam yang belum pernah mempelajari topik nisbah dan kadaran mempunyai pelbagai strategi informal berkaitan nisbah dan kadaran serta berkebolehan menyelesaikan masalah yang memerlukan penaakulan perkadaran. Beliau mendapati murid sekurang-kurangnya menunjukkan tahap pra penaakulan perkadaran dengan menggunakan pengetahuan intuitif, mengemukakan sama ada rajah, jadual, carta, dan model, dan mempamerkan pemikiran relatif. Kaput dan West (1994) pula mencadangkan tiga jenis strategi informal dalam penaakulan perkadaran, iaitu proses koordinasi build-up/build-down, proses singkatan build-up/build-down, dan strategi faktor unit. Mengetahui bagaimana murid menggunakan strategi informal tentang perkadaran dapat membekalkan informasi kepada guru dalam mengembangkan pengetahuan dan strategi informal kepada bentuk yang lebih formal, sekaligus membantu murid dalam pembelajaran topik nisbah dan kadaran (DeCorte, Greer, \& Verscahffel, 1996).

\subsection{METODOLOGI}

\section{Sample dan Lokasi Kajian}

Kajian ini melibatkan murid Tahun Lima Sekolah Rendah (SR) di Wilayah Persekutuan Kuala Lumpur yang dipilih menggunakan teknik pensampelan bertujuan. Pemilihan dibuat menggunakan teknik pensampelan bertujuan membolehkan pengkaji memilih peserta kajian dan lokasi yang menepati kriteria kajian selain membekalkan maklumat yang kaya dan mencukupi daripada peserta sekaligus dapat menjawab persoalan kajian. Kesemua peserta kajian belum pernah didedahkan dengan masalah berkaitan perkadaran. Oleh kerana kajian ini masih di peringkat preliminari, maka artikel ini hanya melaporkan respons bagi tiga peserta kajian, iaitu S1, S2, dan S3. Bermula dari bahagian ini, peserta kajian akan dirujuk sebagai murid.

\section{Rekabentuk Kajian}

Kajian ini menggunakan reka bentuk kajian kes kualitatif bertujuan mengenal pasti strategi informal dan justifikasi yang ditunjukkan oleh murid Tahun Lima semasa menyelesaikan masalah berkaitan perkadaran. Reka bentuk kajian kes kualitatif memerlukan pengkaji meneroka sesuatu kes melalui pengumpulan data terperinci (Creswell, 2012) dan memberi peluang kepada pengkaji untuk mendapatkan maklumat yang lebih mendalam tentang pemikiran murid (Merriam, 2009).

\section{Instrumen}

Kajian ini menggunakan soalan jenis terbuka (open-ended) berkaitan masalah perkadaran, iaitu membandingkan nisbah. Soalan jenis ini membolehkan murid menyumbang sebanyak mungkin maklumat dan membolehkan pengkaji menggunakan teknik probing untuk soalan susulan (Gall, Gall, \& Borg 2003). Kajian ini melibatkan dua tugas membandingkan nisbah, iaitu tugas Jus oren diadaptasi daripada Harel, Behr, Lesh, dan Post (1994) dan tugas Kongsi Piza yang diadaptasi daripada Lamon (1993). Tugas Jus Oren mengkehendaki murid membandingkan rasa jus oren antara Jojo dan Maria. Resepi jus oren Jojo menggunakan tiga cawan pekatan oren dan dua jag air, manakala resepi Maria memerlukan tiga cawan pekatan oren dan empat jag air. Bagi tugas Kongsi Piza, murid perlu menentukan siapa yang makan lebih banyak piza dengan membandingkan dua situasi: satu piza dikongsi dengan 3 budak lelaki; dan tiga piza dikongsi tujuh budak perempuan. Kedua-dua tugas membabitkan konteks masalah yang telah biasa ditemui murid dalam kehidupan harian.

\section{Pengumpulan Data dan Analisis Data}

Data kajian ini dikumpul melalui teknik temu bual klinikal yang merangkumi maklumat lisan dan maklumat bukan lisan. Istilah 'klinikal' bermaksud pemerhatian langsung tingkah laku murid dalam konteks interaksi satu dengan satu. Maklumat lisan adalah apa saja yang dituturkan oleh murid sepanjang sesi temu bual berlangsung selama 30 minit hingga 40 minit. Manakala maklumat bukan lisan merujuk lukisan atau lakaran murid, catatan penemu bual, catatan dan tingkah laku murid. Oleh kerana pengkaji akan merumus andaian tentang pemahaman informal dan strategi penyelesaian murid berkaitan masalah perkadaran bagi setiap aktiviti matematik yang ditunjukkan, maka pengkaji berkemungkinan akan bertanya soalan tambahan atau soalan spontan. Data yang diperolehi akan dianalisis dengan 
mempertimbangkan respons murid berdasarkan strategi penyelesaian, apa juga bentuk perwakilan sama ada rajah, jadual, carta, dan model yang ditunjuk oleh murid, dan justifikasi semasa menyelesaikan masalah perkadaran.

\subsection{DAPATAN DAN PERBINCANGAN}

\section{Tugas Jus Oren}

Strategi penyelesaian: S1 dilihat membuat perbandingan antara dua jus oren secara kualitatif tanpa mengemukakan sebarang bentuk pengiraan, rajah, mahupun model untuk menerangkan konteks masalah. Beliau menggunakan beberapa perkataan, seperti "tawar", "rasa pekat', dan "lebih satu cawan" bagi menggambarkan rasa jus oren. Pengkaji seterusnya memberi soalan tambahan kepada S1 bagi mengetahui apa yang berlaku jika satu lagi cawan pekatan oren ditambahkan kepada resepi Jojo. S1 didapati membandingkan bilangan jag air dan bukannya bilangan cawan oren dengan kenyataan "selalunya kalau saya bancuh Ribena, saya letak air sikit supaya rasa pekat". Bagi S2 pula, beliau membandingkan rasa jus oren menggunakan strategi faktor unit dengan menentukan jumlah pekatan oren yang diperlukan bagi setiap jag air, iaitu membandingkan 1 1/2 cawan pekatan oren Jojo dengan 1 1/3 cawan pekatan oren Maria secara membandingkan penyebut keduadua pecahan. Menurut S2, “1/2 lebih besar dari 1/3", iaitu jus oren Jojo lebih rasa oren. S3 mempamerkan strategi yang berbeza berbanding $\mathrm{S} 1$ dan S2. Beliau dilihat menulis pasangan "1 jag - 1 1/2, 2 jag - 3, 3 jag - 4 1/2" yang menggambarkan hubungan bilangan jag air dan bilangan cawan oren yang diperlukan dan menyatakan resipi jus oren Jojo lebih pekat berbanding resepi Maria.

Justifikasi: Justifikasi yang dikemukakan oleh murid S1 adalah berfokuskan bilangan cawan pekatan oren. Menurut beliau "lagi banyak cawan oren, lagi pekat rasa jus oren" dan oleh kerana bilangan cawan pekatan oren Maria kurang satu berbanding bilangan cawan pekatan jus oren Jojo, maka jus oren Maria akan "rasa tawar". Bagi soalan tambahan, S1 tidak membandingkan bilangan cawan pekatan oren seperti sebelumnya tetapi menggunakan pengalaman peribadi beliau untuk menggambarkan rasa jus oren. Beliau memberi justifikasi bahawa jika bilangan cawan pekatan oren Jojo dan Maria sama banyak, maka jus oren yang menggunakan sedikit jag air akan berasa lebih pekat. Berbeza dengan S1, pernyataan S2 bahawa 1/2 lebih besar dari 1/3 disokong dengan melukis dua bulatan sama saiz dengan setiap satu dibahagikan kepada dua dan tiga bahagian. S2 membuat keputusan resepi Jojo rasa lebih pekat berdasarkan rajah yang menunjukkan bahagian $1 / 2$ lebih besar dari 1/3. Menurut S3, apabila membina pasangan jag air dan cawan oren, beliau tahu bahawa tiga jag air Maria memerlukan empat setengah cawan pekatan oren, tetapi Maria hanya mempunyai empat cawan pekatan oren. S3 membuat keputusan resipi jus oren Jojo lebih pekat berbanding resepi Maria berdasarkan pasangan jag air dan cawan pekatan oren.

\section{Tugas Kongsi Pizza}

Strategi penyelesaian: Dua murid, S1 dan S2 diperhatikan menggunakan strategi faktor unit untuk mencari hubungan bahagian piza bagi setiap budak lelaki dan budak perempuan sebelum membuat keputusan siapa yang makan lebih banyak. Mereka memulakan strategi dengan memotong piza kepada beberapa bahagian kecil untuk diagihkan kepada setiap budak lelaki dan perempuan. S1 membandingkan lebihan bahagian piza selepas membahagikan setiap satu piza budak lelaki dan budak perempuan kepada empat bahagian. Seterusnya S1 membandingkan $1 / 4$ lebihan piza budak lelaki dan 1/8 lebihan piza budak perempuan dalam bentuk dua rajah bulatan masing-masing dipotong kepada empat dan lapan bahagian. S2 dengan mudah memperolehi 1/3 piza untuk setiap budak lelaki dan 1/7 piza untuk setiap budak perempuan tetapi tidak terus membanding kedua-dua nisbah tersebut. Beliau hanya membandingkan kedua-dua nisbah setelah menyamakan kedua-dua penyebut melalui pengiraan untuk memperolehi kesetaraan pecahan. Berbeza dengan S1 dan S2, S3 memaparkan strategi penyelesaian secara membina pasangan " 3 orang -1 piza, 6 orang -2 piza" dan menyatakan budak perempuan makan sedikit piza berbanding budak lelaki. Apabila pengkaji bertanya berapa "sedikit" piza yang dimakan oleh budak perempuan berbanding lelaki, S3 menambah satu lagi pasangan "9 orang - 3 piza" sambil menggelengkan kepala.

Justifikasi: Apabila ditanya mengapa S1 membahagikan satu piza kepada empat bahagian, beliau mengaitkan pengalaman peribadi dengan menyatakan "di restoran piza satu piza kecil akan dipotong kepada 4 bahagian". S1 memberi alasan bahawa budak lelaki makan piza lebih banyak berbanding budak perempuan berdasarkan rajah yang menunjukkan bahagian 1/4 lebih besar dari 1/8. Menurut S2 perbandingan nisbah hanya boleh dilakukan setelah penyebut 1/3 dan 1/7 disamakan. Beliau menerangkan bahawa apabila penyebut kedua-dua pecahan (nisbah) sama, ini bermakna setiap piza dipotong dengan saiz yang sama dan seterusnya merumuskan budak lelaki makan lebih piza berbanding budak lelaki. S3 menjelaskan beliau membina pasangan " 3 orang -1 piza, 6 orang - 2 piza" dengan menggandakan tiga orang kepada enam orang dan melakukan gandaan yang sama bagi bilangan piza. Menurut S3, dua piza hanya cukup dimakan oleh enam orang sahaja sedangkan bilangan budak perempuan adalah tujuh orang. Beliau menambah, terdapat seorang budak perempuan yang tidak dapat makan piza, maka beliau membuat keputusan bahawa budak lelaki makan lebih banyak piza. Walaupun jawapan yang diberi S3 adalah tepat, namun beliau tidak dapat menyatakan beza bahagian piza yang dimakan oleh budak lelaki dengan memberi justifikasi tujuh tidak terdapat dalam gandaan tiga.

\subsection{RUMUSAN}

Dapatan kajian menunjukkan bahawa murid seawal usia 11 tahun berkeupayaan menyelesaikan masalah berkaitan perkadaran walaupun belum mempelajari secara formal. Murid bukan sahaja memaparkan pelbagai strategi informal, malah boleh memberi justifikasi bagi menyokong pernyataan yang dibuat. Strategi penyelesaian yang ditunjukkan murid selari dengan strategi informal penaakulan perkadaran yang dicadangkan oleh Lamon (1993) dan Kaput dan West (1994). Dalam kedua-dua tugas, strategi S1 boleh dikategorikan sebagai pra penaakulan perkadaran yang mana beliau mengaitkan pengetahuan intuitif dan menaakul secara kualitatif (verbal) selain turut mengemukakan rajah. S1 juga berkebolehn menggunakan strategi faktor unit bagi tugas Kongsi piza. S2 pula dilihat menyelesaikan keduadua tugas menggunakan strategi yang sama, iaitu strategi faktor unit. Sementara itu, strategi yang dipamerkan oleh S3 bagi kedua-dua tugas boleh diklasifikasikan sebagai strategi singkatan build-up. 
Dapatan kajian juga menunjukkan strategi informal penaakulan perkadaran berkait dengan beberapa elemen penaakulan perkadaran seperti yang dicadangkan oleh Lamon (1993). Strategi faktor unit yang dipamerkan oleh murid membabitkan beberapa elemen penaakulan perkadaran, seperti unitizing, pemetakan, dan kuantiti dan perubahan. Manakala strategi singkatan build-up sangat berkait dengan konsep unitizing. Bagi murid yang menaakul secara kualitatif dan menggunakan pengetahuan intuitif, mereka bukan sahaja boleh mengenal pasti dua kuantiti, malah tahu perubahan bagi sesuatu kuantiti.

Salah satu implikasi daripada dapatan kajian adalah guru perlu menyediakan pelbagai bentuk tugasan berkaitan penaakulan perkadaran yang dapat mencungkil pemahaman murid tentang perkadaran seterusnya menggalakkan murid berfikir secara perkadaran.

\section{Rujukan}

Ben-Chaim, D., Fey, J. T., Fitzgerald, W. M., Benedetto, C., \& Miller, J. (1998). Proportional Reasoning Among 7th Grade Students With Different Curricular Experiences. Educational Studies in Mathematics, 36, 247-273.

Christou, C., \& Philippou, G. (2002). Mapping And Development Of Intuitive Proportional Thinking. Journal of Mathematical Behavior, 20, $321-336$.

Cramer, K., Post, T., \& Currier, S. (1993). Learning and Teaching Ratio and Proportion: Research Implications. Dalam Research Ideas for the Classroom, 159-178. New York: Macmillan Publishing Company.

Creswell, J. W. (2012). Qualitative Inquiry And Research Design: Choosing Among The Five Traditions (3rd ed.). Thousand Oaks, CA: Sage.

DeCorte, E., Greer, B., \& Verschaffel, L. (1996). Mathematics Learning And Teaching. Dalam D. Berliner \& R. Calfee (Eds.), Handbook of Educational Psychology, 491-549. New York: Macmillan.

Fuson, K. C., \& Abrahamson, D. (2005). Understanding Ratio And Proportion As An Example Of The Apprehending Zone And Conceptual-Phase Problem-Solving Models. Dalam J. Campbell (Ed.), Handbook Of Mathematical Cognition, 213-234. New York: Psychology Press.

Gall, M. D., Gall, J. P., \& Borg, W. R. (2003). Educational research: An introduction (7th ed.). Boston, MA: A \& B Publications

Harel, G., Behr, M., Lesh, R., \& Post, T. (1994). Invariance Of Ratio: The Case Of Children's Anticipatory Scheme Of Constancy Of Taste. Journal for Research in Mathematics Education, 25, 324-45.

Heller, P. M., Post, T. R., Behr, M., \& Lesh, R. (1990). Qualitative And Numerical Reasoning About Fractions And Rates By Seventh- And Eighth-Grade Students. Journal for Research in Mathematics Education, 21(5), 388-402.

Kaput, J. J., \& West, M. M. (1994). Missing-Value Proportional Reasoning Problems: Factors Affecting Informal Reasoning Patterns. Dalam G. Harel \& J. Confrey (Eds.), The Development Of Multiplicative Reasoning In The Learning Of Mathematics 235-287. Albany, NY: State University of New York Press.

Kementerian Pendidikan Malaysia. (2013). Draf Kurikulum Standard Sekolah Rendah: Dokumen Standard Kurikulum dan Pentaksiran Matematik Tahun Empat. Kuala Lumpur: Bahagian Pembangunan Kurikulum.

Lamon, S. J. (1993). Ratio And Proportion: Connecting Content And Children's Thinking. Journal for Research in Mathematics Education, 24(1), 41-61.

Lamon, S. J. (2007). Rational Numbers And Proportional Reasoning: Toward A Theoretical Framework For Research. Dalam F. K.

Lester (Ed.) Second Handbook Of Research On Mathematics Teaching And Learning, 1, 629-668. Charlotte, NC: Information Age Publishing.

Lara Roth, S. M. (2006). Young Children's Beliefs About Arithmetic And Algebra. Tesis Ph.D tidak diterbitkan, Tufts University.

Lesh, R., Post, T., \& Behr, M. (1988). Proportional Reasoning. Dalam J. Hiebert \& M. Behr (Eds.) Number Concepts And Operations In The Middle Grades (h. 93118). Reston, VA: Lawrence Erlbaum \& National Council of Teachers of Mathematics.

Merriam. S. B. (2009). Qualitative Research: A Guide To Design And Implementation. San Francisco, CA: Jossey-Bass.

Misailidou, C, \& Williams, J. (2003). Diagnostic Assessment Of Children's Proportional Reasoning. Journal of Mathematical Behavior, $22,335-368$.

National Mathematics Advisory Panel. (2008). Foundations For Success: The Final Report of the National Mathematics Advisory Panel. Washington, DC: U.S. Department of Education. 